Thomas M. Dousa (tdousa2@uiuc.edu) University of Illinois, Urbana-Champaign, Champaign IL USA

\title{
Concretes, Countries, and Processes in Julius O. Kaiser's Theory of Systematic Indexing: A Case Study in the Definition of General Categories
}

\begin{abstract}
Although general categories are an important feature of many KOSs, they are difficult to define. If we are to understand the factors that render category definition difficult, we should consider how designers of past KOSs have defined the categories in their systems. This paper presents, as a case study, an analysis of the formulation of categories in J. Kaiser's theory of systematic indexing, which was designed for the indexing of commercial literature. Kaiser's theory posited three categories: concretes, countries, and processes. Close examination of his writings reveals semantic tensions in the definition of each category. Concretes were defined both in general terms as things-in-the-world and in domainspecific terms as commodities; Countries were defined as political units but included geographical regions that were not politically unified; and Processes were defined alternately as conditions of concretes or actions associated with them. Tensions also appear in the categorial scheme comprising these categories, of which there were dyadic (Concrete-Process) and triadic (Concrete-Country-Process), the former of which was grounded on a theoretical model and the latter, on pragmatic, domain-specific considerations. Kaiser's attempts to harmonize these models by deriving countries from concretes faltered because of his narrow construal of concretes. The tensions in Kaiser's definition of categories are due to semantic overdetermination, while those associated with his categorial scheme are ascribable to the general tension between theory and practice.
\end{abstract}

\section{Introduction}

General categories - or fundamental categories, as they are known in the tradition of facet analysis (La Barre 2010, 250-251) — are a basic structural feature of many knowledge organization systems (KOSs). They play important semantic and syntactic roles in the constitution of such systems, serving both as a means of partitioning, and organizing, isolate concepts into broader classes and as the basis for developing the citation order of individual elements within compound indexing terms (Vlasák 1967; Cheti 1990; Svenonius 2000, 57-58). Accordingly, the choice and definition of general categories is of cardinal importance in shaping both the form and content of KOSs. It is striking, then, that, as Svenonius (1979) has documented, designers of classification and indexing schemes have often experienced difficulties in generating fully satisfactory definitions for the categories underlying their KOSs. How is one to account for this phenomenon? Svenonius suggested that problems with category definition are to be attributed to the fact that "[f]or the most part, the metaphysics underlying index languages has been of an amateur or common sense type" (p. 74). This may well provide a general explanation for deficiencies in the definition of categories in past KOSs: however, in its very generality, it provides little information about the specific factors that have led to problems in definition within individual systems. If we are to come to a fuller understanding of these factors, it is necessary to descend to particulars and to examine, at close range, the formulation of categories in specific KOSs. Detailed analysis of category formation in individual systems that takes into account not only their systematic and theoretical features but also the historical 
Thomas M. Dousa. 2011. Concretes, countries, and processes in Julius O. Kaiser's Theory of Systematic Indexing: A case study in the definition of general categories. In Smiraglia, Richard P., ed. Proceedings from North American Symposium on Knowledge

Organization, Vol. 3. Toronto, Canada, pp. 160-173.

contexts within which they were developed, can provide an empirically founded evidentiary base for thinking through the problems of category formation.

In this paper, I offer a case study in the analysis of the formulation of general categories in a single, historically significant KOS. As the object of examination, I have chosen the method of alphabetico-specific systematic indexing created by Julius Otto Kaiser (1868-1927), which he developed in the course of a career as a librarian and indexer working in commercial and technical libraries and information bureaux. Acknowledged by some scholars to be the first KOS explicitly based on a theory of general categories (e.g., Vlasák 1967, 152-153; Svenonius 2000, 6), Kaiser's method is an ideal field for analysis of category definition for two reasons, one structural and the other historical. First, unlike later KOSs, it is relatively simple in its structure. Kaiser posited that the terms in an indexing language can be partitioned into three categoriesterms for concretes, terms for countries, and terms for processes - and that these categories are to be combined into a limited set of schemata for compound subject strings — or, to use his preferred term, statements - , all ultimately derived from the basic citation order of concretecountry-process (Kaiser 1911, $\S 301-302$ ). Because of this structural simplicity, it is fairly easy to get an analytical purchase on how the categories functioned as a system. Second, Kaiser $(1908,1911,1926)$ sought to explain and justify, in considerable detail, his system of categories in a series of publications extending over a number of years: these writings constitute a rich documentary dossier for tracing the definitional contours of the categories in his system. A close examination of Kaiser's texts reveals inner tensions not only in his conceptualization of the semantic content of individual categories but in his articulation of his category system as a whole. By considering, in turn, the three elements of his category scheme and then the scheme as a whole, we can explore these tensions and draw some preliminary conclusions about the factors that contributed to the difficulties that he encountered in category definition.

\section{The Category of "Concrete"}

The first and most prominent category in Kaiser's scheme is that of terms denoting what he called concretes: these constituted "the main term" of statements that determined their place within an alphabetically-ordered index (Kaiser 1911, § 313). Kaiser's choice of "concrete" as a technical term may seem unusual to readers today; to understand what expectations the word would have raised in the minds of his contemporaries, it is necessary to consider briefly its lexicographical background.

The term "concrete" ultimately derives from philosophical discourse, where it had long stood in opposition to the term "abstract" (Barata-Moura 2009). In particular, traditional logical doctrine distinguishes between "concrete terms" and "abstract terms". The former serve as names of things - that is to say, as names of (kinds of) entities capable of having an independent existence-while the latter function as names of the attributes of things viewed in separation from the things to which they belong (e.g., Mill 1874, 33-34; Ryland 1900, 23, 25; Joseph 1906, 18): for example, "Socrates" and "human being" are concrete terms, while "humanity" or "rationality" are abstract terms. This logico-linguistic notion of "concrete" is closely bound up with the ontological notion of things as individuable (kinds of) entities and bears some analogy to the Aristotelian notion of substance (Stock 1888, 20, 26; Joseph 1906, 22-23, 40-44): like the latter, it can be applied to individual objects in the world (i.e., Aristotle's first substances, such as "Socrates" or "this fern on my desk") or to specific kinds of objects (i.e., Aristotle's second substances, such as "human being" and "fern"). 
Thomas M. Dousa. 2011. Concretes, countries, and processes in Julius O. Kaiser's Theory of Systematic Indexing: A case study in the definition of general categories. In Smiraglia, Richard P., ed. Proceedings from North American Symposium on Knowledge

Organization, Vol. 3. Toronto, Canada, pp. 160-173.

In the parlance of the textbooks of traditional logic circulating in the late $19^{\text {th }}$ and early $20^{\text {th }}$ centuries, then, to be a concrete thing, or a concrete, was to be a particular (kind of) thing capable of independent existence as a discrete whole. This logical terminology left its imprint on the discourse of allied but distinct fields, such as grammar (see, e.g., Spiess \& Moritz 1869, 3-4; Zikmund 1876, 25; Martin 1892, 59-60) and, more interestingly for our purposes, library cataloging and classification: for instance, both Cutter (1904, 23, s.v. "Subject") and Brown (1906, 8-9) spoke of "concrete subjects" encompassing specific kinds of things (e.g., "Roses", "Horses", "Cats") and individual entities (e.g. "Shakespeare", "England"). Furthermore, in popular discourse, the term "concrete" was applied to objects "existing in a material form or as an actual reality" (Simpson \& Weiner 1989, vol. 3, 673a, 5 s.v. "concrete"). This nuance, which bestowed upon the word a distinctly materialist flavor, also foregrounded its association with "particular" and "individual" objects in the world (Whitney \& Smith 1911, vol. 2, 1170, 2 s.v. "concrete"): to many of Kaiser's contemporaries, it was the particular objects and phenomena encountered in one's lived experience of the natural world that counted as concrete things, or concretes.

At first blush, Kaiser's definition of concretes followed, in its general outlines, the various understandings of the term sketched out above. Specifying that, in his parlance, the term "concretes" was to be understood in the sense of "concrete existences", he took the term to refer to "things in general, real or imaginary" knowable by observation and reasoning (Kaiser 1926, $23, \S 10 ; 1911, \S 52$ [emphasis his]). The stipulation that concretes, qua things, can be "imaginary" as well as "real" belies the popular view that they are actual entities encountered in the natural world: it is consonant, however, with the more technical philosophical definition of a thing as "any object of thought that can be conceived of as having an individual existence, whether in the world of perception or the world of imagination" (Ryland 1900, 25; cf. Stock $1889,20, \S \S 78,80)$. Yet, despite this definitional nod towards an all-encompassing notion of concretes as things simpliciter, Kaiser appears, in practice, to have viewed them in more material terms. "The ... term "things", he stated, "implies a substance, a concrete article" - that is to say, it ought to be applied to physical, tangible entities (Kaiser 1911, § 299) — and it is worth noting that the French translation of his first book translated "concretes" as "matières" (Kaiser 1914, $\S$ 114). Furthermore, among the key properties of concretes that he identified were the facts that "they occupy a space, they have a form", with the result that "[e]ach concrete represents something definite to handle" (Kaiser 1911, § 109). Such a characterization of concretes clearly echoes the popular view of concrete beings as individual entities existent in the natural world. However, for the purposes of indexing, terms for concretes were not to refer to individual things in the world but rather to specific kinds of things, such as "money", "machine", "iron", "scientific instrument", "yarn", and so on ( $(73)$ : in other words, they were largely limited to what logicians called "concrete general” terms (Mill 1874, 35; Read 1898, 29-30).

At a general level, then, terms for concretes, in Kaiser's view, referred to types of things in the world. However, this is not the only definition of concretes to be found in his works. In his earliest published discussion of his indexing system, which appeared 1908, Kaiser (1908, § 366, s.v. "Concretes") defined concretes as "any saleable commodity, goods, etc., but also including persons whose labour is a saleable commodity". This definition would continue to appear alongside the more general one of concretes as things in his subsequent writings: in 1911, Kaiser characterized terms for concretes in indexing as referring to "the commodities with which [one] is concerned" (Kaiser 1911, $\S 73$ ), while, in 1926, in the course of a retrospective account of how he had developed his indexing method, he reminisced that, in the original version of his system, 
Thomas M. Dousa. 2011. Concretes, countries, and processes in Julius O. Kaiser's Theory of Systematic Indexing: A case study in the definition of general categories. In Smiraglia, Richard P., ed. Proceedings from North American Symposium on Knowledge

Organization, Vol. 3. Toronto, Canada, pp. 160-173.

he had distinguished "terms of commodities" from "terms of action or verbs", with the former eventually developing into the category of terms for concretes (Kaiser 1926, 22-23 $\S 7,10$ ). Needless to say, things and commodities are not convertible concepts. Whereas, arguably, commodities can, in most cases, be reduced to things, be they real or imaginary, it is not the case that all things are commodities: for example, antelopes or coelocanths are tangible things but are not commodities, unless they have been captured, placed in the ownership of a person (individual or corporate), and earmarked for exchange in a market. The definition of concretes as commodities, then, narrows the semantic scope of the category from the broader range of "things, real or imaginary".

The passage from the general definition of concretes as things-in-the-world to the specific one of concretes as commodities was neither adventitious nor the result of conceptual inconsistency on Kaiser's part; rather, it resulted from his adoption of a particular perspective, which he neatly summarized as follows: "The ... term 'things' implies a substance, a concrete article. In business there is but one kind of articles - commodities having an exchange value" (Kaiser 1911, § 299). As the opening phrase of the second statement clearly indicates, Kaiser's interpretation of concretes as commodities was domain-specific in nature, reflecting the field of interest of businessmen. Given the fact that Kaiser developed his method of indexing while working at commercially-oriented institutions such as the Philadelphia Commercial Museum (1896-1899); the Commercial Intelligence Bureau, Ltd., in London (ca. 1900-1902); British Westinghouse (ca. 1903); and the Tariff Commission in London (1904-1911) (American Society of Mechanical Engineers 1928), it is unsurprising that many of its features were formulated expressly from a business point of view (ef., e.g., Kaiser 1911, $\S$ 97, 242, 247-249, 296, 663, s.v. "Business library" \& "Business literature"; 1927, 26, $\S 18,20)$ : indeed, his view of commodities as concretes par excellence is best understood as a reflection of the professional milieux within which he worked. At any rate, the result was that Kaiser's writings gave a two-tiered definition of concretes - a general one that understood them as things in general and a domain-specific one that interpreted them as commodities. Fatefully, in terms of definitional issues, it was the latter definition that he would elaborate.

In the first published discussion of the category system underlying his indexing method, Kaiser (1908, $\S \S 114,366$, s.v. "Concretes") limited himself to noting that the terms for concretes qua commodities included not only names for (types of) commodities but also the names of the occupational classes of persons whose labor could be viewed as a type of commodity. Three years later, he offered a more extensive account of the category, subdividing it into three subclasses: movable concretes, immovable concretes, and abstract concretes (Kaiser 1911, §§ 299, 316). Of these classes, the first two - movable and immovable concretes - were doubtless inspired by the traditional distinction between immovable and immovable things in the law of property (e.g., Austin 1873, vol. 2, 805; Robinson 1900, 120-121; Salmond 1907, 396399), even if they did not correspond in all particulars to these legal antecedents. Movable concretes, Kaiser stipulated, "include merchandise in the widest sense": among the terms for such concretes that he gave as examples are "silk", "hardware", "paper", "money", "gold", and "machine" (Kaiser 1911, § 299, 316). Terms for immovable concretes, on the other hand, are to refer "mainly [to] what is called physical features of countries", such as "land", "river", "resources", and "harbour" (§ 316), although an example such as "markets" (§ 452) appears to go beyond physical features and enter into the realm of socio-economic arrangements. As regards the paradoxically-named abstract concretes, some commentators have taken them to refer to "abstract terms that do not represent action" (e.g., Vlasák 1967, 153; Straioto \& Guimarães 
Thomas M. Dousa. 2011. Concretes, countries, and processes in Julius O. Kaiser's Theory of Systematic Indexing: A case study in the definition of general categories. In Smiraglia, Richard P., ed. Proceedings from North American Symposium on Knowledge

Organization, Vol. 3. Toronto, Canada, pp. 160-173.

2004, 111). Some of the examples given by Kaiser (1911) — such as "information" (§ 73), "loan" (§ 344), and "credit" (§ 457) — are indeed consonant with this an interpretation. However, as Kaiser himself insisted, this class "is mainly concerned with the various forms of human energy" expended as labour $(\S \S 316,299)$. Terms for abstract concretes pertaining to labour could refer to "labour" itself ( $(496)$ but more frequently named classes of workers-such as "commercial traveler", "engineer", "foreman", "manager", or "typist": in all the latter cases, Kaiser was quick to point out, it was the energy put forth in the work, not the worker himself, that was to be viewed as the "real commodity" (§ 326).

Whether a concrete be classified as movable, immovable, or abstract, Kaiser took it to be a commodity - an interpretation easier to apply consistently to movable and abstract concretes, which were defined in terms of commercial exchange, than to immovable ones, which were defined largely in terms of physical features, not all of which are amenable to serving as the object of trucking and bartering (e.g., rivers and harbours). In time, however, the category's semantic center of gravity underwent a shift. In his final published discussion of systematic indexing, Kaiser (1926, 23, § 10) conceded that "[c]ommodities unfortunately do not exhaust the list of possible terms for main headings" in an alphabetically-ordered index, for "there are others that are just as important". These other terms he identified as referring to "Energy of some kind", such as "Labour, Power, Light, etc" (p. 23, § 10). Thus, Kaiser amended his previous view that all concretes are commodities to the position that the class of terms for concretes comprises two subclasses - "[t] erms of commodities and terms of energies" (p. 23, $\S 10$ ). He appears to have been reluctant to do so, for he added the parenthetical comment that "[i]nclusion of energy is forced, because commodities comprise latent energy" (p. 23, § 10). This statement is noteworthy, because, in reducing commodities to forms of latent energy, Kaiser gave, in effect, precedence to the concept of energy in the semantic constitution of the category of concretes: in place of concretes qua commodities, of which human energy constitutes a subset, we now have concretes qua forms of energy, of which commodities are one manifestation. Although Kaiser did not develop this idea further, it is apparent that a definition of concretes as forms of energy widened the applicability of the category beyond the domain of business to encompass the whole of the physical world.

In fine, we can see that, despite the stability of the label "concretes" across Kaiser's writings, the category of concretes actually was defined in at least three different ways: (1) broadly, as a universal category encompassing terms for things in the world; (2) narrowly, as a domainspecific category comprising terms for commodities; and (3), in a manner jointly broad and narrow, as a composite category containing terms for commodities and energies alike, with the latter, however, functioning as the de facto basis for the former. As we shall presently see, the oscillation between general and domain-specific definitions of "concretes" would affect Kaiser's arguments regarding the category of countries.

\section{The Category of “Country"}

In comparison to establishing the definition of concretes, doing so for the category of countries would seem to be a comparatively simple matter: Kaiser (1926, 24, § 15(c)), at any rate, considered that, as a category for indexing, "countries ... do not lead to any difficulties". His definition, however, again reveals domain-specific considerations embedded within a category of ostensibly general scope. Characterized in most general terms, terms for countries simply "indicat[e] the localities with which ... concretes are connected" (Kaiser 1911, § 73). These localities, however, are localities of a special sort, for, as Kaiser went on to specify, "[t]he 
Thomas M. Dousa. 2011. Concretes, countries, and processes in Julius O. Kaiser's Theory of Systematic Indexing: A case study in the definition of general categories. In Smiraglia, Richard P., ed. Proceedings from North American Symposium on Knowledge

Organization, Vol. 3. Toronto, Canada, pp. 160-173.

country is in most cases a political division of territory having an independent government, at least independent enough to frame its own customs tariff; but sometimes it is a continent or a number of disconnected territories" ( $\$ 332)$.

This latter definition is worth unpacking. On one hand, it takes a country, stricto sensu, to be a political entity covering a bounded territory and possessing an independent government —a definition that seems general in scope and might be acceptable in a number of different domains. On the other, Kaiser's stipulation that a political territory is to be considered independent insomuch as it generates and maintains its own customs tariff clearly slanted the definition towards the domain of commercial interests. At any rate, the stipulation permitted the inclusion not only of terms such as "United States of America" and "United Kingdom", which designated political units enjoying complete political sovereignty, but also "German South West Africa" and "Dutch East Indies", where a measure of economic independence with regard to tariffs existed within a broader framework of colonial dependence (Kaiser 1911, § 332). The admission of terms for continents — such as "Europe" or "South America" (§ 332)—and disconnected territories - such as "Colonies", which might share dependence on a power but be scattered in different geographical regions $(\S 332)$ - into the category of countries clearly constituted two exceptions to the general definition, for neither is necessarily connected to the idea of a politically distinct entity possessing an independent government. However, for indexing purposes, it was necessary to include such geographical units, for they might be used to characterizing markets with which different kinds of commodities are located — one need think only of locutions such as "the South American market" or, for the British of the early $20^{\text {th }}$ century, the "Colonial market". Clearly, domain-specific considerations here led Kaiser to sacrifice the theoretical purity of the category's definition in favor of a hybrid definition that was sufficiently inclusive to be pragmatically useful in indicating "the localities with which ... concretes are located".

Whatever theoretical difficulties Kaiser may have made in shaping the inner contours of the definition of countries to suit the practical exigencies of his indexing system, they paled in comparison to the problem of the status of the category itself. In his earliest discussion of the categories, he treated countries as a category distinct from, and coordinate to, that of concretes. He did aver, however, that, from a purely syntactic point of view, terms for countries and countries could occupy the same positions within a statement: thus, statements could take the form Country-Concrete-Process, as well as the archetypal Concrete-Country-Process (Kaiser $1908, \S \S 114-115,142)$. Three years later, however, Kaiser $(1911, \S 300)$ took the category of countries to constitute a special, though distinct, form of concretes, arguing that

Immovable commodities include one kind of special importance-countries in the political sense. Their peculiarity is to be sought not so much in their territories, but more especially in the authority exercised within each territory as expressed in their laws etc. In addition there are the peculiarities of the inhabitants as expressed in their language, customs and habits. For these reasons we are obliged to treat the political divisions called countries as a distinct class.

This argument seeks to preserve the distinctness of the categories of countries while deriving it from the category of concretes: few, if any, of Kaiser's readers will find it persuasive. The primary reason for its implausibility lies in Kaiser's commitment to a narrow, domain-specific definition of concretes as commodities. Even if one grants that physical features of a country- 
for example, its resources — can be considered to constitute immovable commodities, countries are not, as a rule, considered to constitute commodities themselves: indeed, it requires a good deal of intellectual gyrations to come to the idea that a politico-legal unit of national scope possessing a territory and a population with distinct cultural traits can be accommodated under even the broadest definitions of "commodity" available, such as "anything that is useful, convenient, or serviceable" (Whitney \& Smith 1911, 1132, 3 s.v. "commodity"). Adoption of a more general definition of concretes as things-in-the-world would have greatly strengthened Kaiser's essay at deriving countries from concretes, even if it is doubtful that such a move would have resolved all difficulties. However this may be, it is evident that the tension between general and domain-specific understandings of how a concrete is to be defined left its imprint on Kaiser's account of countries.

Ultimately, Kaiser's attempt at grounding the category of countries in that of concretes did not have any discernible practical effects on the construction of statements, for the syntactic rules governing this procedure held whether countries were derived from concretes or not. This, however, raises a question of motivation: why did Kaiser find it necessary to make the attempt in the first place? Part of the answer probably lies in a desire to provide a semantically-based rationale for the syntactic interchangeability of terms for concretes and terms for countries within indexing statements. More importantly, Kaiser's attempted reduction of countries to concretes must be seen as the key step in an effort to reconcile two different versions of his categorial scheme - one based on a set of three categories and the other based on only two. Before we consider this issue in greater detail, it is necessary to examine Kaiser's definition of the category of processes.

\section{The Category of "Process"}

As was the case with the concept of concretes, it is helpful to look at Kaiser's understanding of what a process is in light of its broader conceptual Umfeld. Over the course of the $19^{\text {th }}$ century, the term "process" - the basic meaning of which is "to go forward" - took on various shades of meaning in ordinary discourse, of which the following three are of especial salience for our purposes (Hunter \& Morris 1897, vol. 3, 3760, 4-6; cf. Simpson \& Weiner 1989, vol. 12, 546, 6 s.v. "process"):

- "A line of action or conduct; a course, a proceeding, an operation"

- "A series of operations or treatment applied to something; a series of actions or experiments: as, a manufacturing process"

- "A series of motions or changes going on in anything, as in growth, decay, \&c. of physical bodies; continuous operation".

All three of these definitions identify processes as actions or operations possessing structure and duration ("a line of action"; "a series of operations"; "a series of actions"; "a series of motions"; "continuous operation"). The latter two go on to associate these actions with entities of some sort ("something" and "anything"), though the relationship between entities and the processes in which they are implicated vary across the definitions. The second definition presents the entity in question as the object of operations or treatments applied to it from the outside, whereas the third 
Thomas M. Dousa. 2011. Concretes, countries, and processes in Julius O. Kaiser's Theory of Systematic Indexing: A case study in the definition of general categories. In Smiraglia, Richard P., ed. Proceedings from North American Symposium on Knowledge

Organization, Vol. 3. Toronto, Canada, pp. 160-173.

depicts it as the substrate of internally generated operations that, in turn, bring about its alteration: in the parlance of the popular philosophy of the time, such processes were classified as "artificial processes" and "natural processes", respectively (e.g., Guthrie 1882, 40). Whether a process was artificial or natural, it ultimately required the presence of some sort of thing that was the source or object of the process of the action: in other words, processes were only conceivable in relation to entities. Such a view is consonant with what one commentator has termed "a substance metaphysic" (Rescher 1996, 35), wherein things are taken to be ontologically prior to processes. Needless to say, it was implicit in the thought of businessmen in the late $19^{\text {th }}$ and early $20^{\text {th }}$ centuries, for whom artificial processes - in particular, manufacturing and commercial processes - served as the means to convert raw materials into products and to situate these latter as commodities into appropriate markets (e.g, Pope 1905, 4; Cowgill 1905): without the raw materials or finished products, there would be no raison d'être for the processes.

Kaiser's understanding of processes generally mirrored the view sketched out above, albeit not without some deviations. For him, the existence of processes depended on that of concretes: in his words, "there can be no process without concrete" (Kaiser 1908, § 115, cf. 1911, § 183). This tenet had consequences both for the syntax and semantics of terms for processes. In regards to syntax, Kaiser stipulated that, as a rule, such terms were to occupy the final place in a statement, thus serving, in effect, as subdivisions of terms for concretes (Kaiser 1911, § 302; 1926, 22-23, §§ 7, 12; cf., however, 1908, § 115; $1911 \S \S 303,322,346,655)$. As for semantics, his definitions of processes were consistently formulated in such a way as to relate the concept of process to that of concrete.

In his earlier writings, Kaiser foregrounded the idea of action as an element in the constitution of the category of processes, stipulating that, in indexing, "[t]he process expresses the action which the concrete is undergoing or has undergone" (Kaiser 1911, § 344; cf. $\S \S 73,302$ ). Examples of processes qua actions included, inter alia, "generation" of electricity ( $\$ 327)$, "description" of gin cotton rollers (§ 462), "manufacture" of rubber in Brazil (§ 481), "farming" of ostriches in Australia ( $(497)$, "establishment" of a commercial museum in Spain ( $(526)$, and "packing" of raw cotton in the United States of America ( $\$ 518)$. To judge by these and other examples of the use of terms for processes within statements given by Kaiser, the actions constituting processes were most often ones performed on a concrete, whether physically (e.g., "manufacture" of rubber) or verbally (e.g., "description" of cotton gin rollers): that is to say, he tended, in practice, to relate the concrete to the process as an object, or passive recipient, of the action: this is consonant with a view that "process terms ... show ... modifications to which [concretes] are subject" (Kaiser 1911, 27, § 21). One can, however, find a few isolated cases where the concrete appears to be acting rather than being acted upon (e.g., $\S \S 459$ ["chemical action" of wrapping paper], 460 [corrosion caused by wrapping paper]) and it is worth noting that, in theory at least, Kaiser admitted actions done by concretes into his armamentarium of processes, glossing "actions" as "what things do or what is done to them" (§301; cf. $\S 55)$. The preponderance of terms for processes as actions done to concretes in Kaiser's examples is best interpreted as reflecting the fact that, from a business point of view, manufacturing and technical processes tended to be viewed as artificial processes acting upon raw materials or commercial products.

Both actions on, and - to a lesser degree - actions by, concretes, then, fell under the rubric of processes. However, they did not exhaust the category, for Kaiser $(1911, \S \S 52,298)$ also defined processes as "the conditions attaching to [concretes]". Now the term "condition" typically implies the idea of a state of being or static quality (cf., e.g., Whitney \& Smith 1911, 
vol. 2, 1174, 1-2 s.v. "condition") and so is semantically distinct from the idea of action. Thus, the definition of processes qua conditions of concretes provided warrant for the inclusion of terms for processes - such as "trade condition" with respect to watches in Switzerland (Kaiser $1911, \S 395)$, "available" with respect to sailing vessels (§ 455), "undesirable" with respect to credit in the Gold Coast ( $\$ 457)$, "unemployment" with respect to labour in the United Kingdom (§ 479), "ownership" with respect to railways in Japan (§ 499), and "qualifications" with respect to commercial travelers in China $(\$ 55)$ - that could not have been accommodated in a category defined in terms of actions alone. In his earlier writings, Kaiser did not discuss his rationale for including terms referring to conditions within the category of processes. In his final article, however, he neatly stated it as follows:

... terms of actions or verbs may be supplemented very conveniently by adding those implying a state or condition generally ... . The two classes of terms, i.e., those of actions and those of states, I have called collectively PROCESSES in the sense of dynamic or static conditions of concretes (Kaiser 1926, 23, § 11 [emphasis his]).

According to this passage, terms referring to the conditions of concretes serve to supplement terms referring to the actions of concretes: they stand in relation to each other as coordinate subclasses of the category of terms for processes, with the latter representing dynamic conditions of concretes and the former, their static conditions. Interestingly, this definition of processes betokens a surreptitious shift in the semantic emphasis of the category. Whereas in his earlier writings, Kaiser had underscored the notion of action as the primary element in the definition of processes, he now accorded pride of place to the notion of condition by redescribing actions as a species of condition - namely, "dynamic conditions" - to be set alongside the well-established species of "static conditions". The definitional contours of the category of process in Kaiser's system were thus no less immune to the process of change than were those of the category of concretes.

\section{Kaiser's Categorial Scheme: Dyadic in Theory and Triadic in Practice}

As we saw earlier, Kaiser considered processes to be inextricably associated with concretes. This had important implications for the theoretical framework of his categorial scheme as a whole. In his most extensive presentation of the theory of systematic indexing, Kaiser (1911) sought to justify his selection of categories with the argument that that they reflect not only the basic contents of human knowledge of the world but also discourse about the world as recorded in the literature that is the proximate object of indexing. This argument can be found in two passages that deserve to be quoted in extenso:

Literature is a record, it is a descriptive record .... What we record is what we observe, what we reason out. The subjects of our observing and reasoning are things in general, real or imaginary, and the conditions attaching to them. We shall call them concretes and processes respectively ( $§ 52$ [emphases his]).

$[F]$ rom the standpoint of knowledge literature is confined to the description of concretes and of the conditions attaching to them, and for our purposes literature may be analysed into terms of concretes and terms of processes. They are the 
Thomas M. Dousa. 2011. Concretes, countries, and processes in Julius O. Kaiser's Theory of Systematic Indexing: A case study in the definition of general categories. In Smiraglia, Richard P., ed. Proceedings from North American Symposium on Knowledge

Organization, Vol. 3. Toronto, Canada, pp. 160-173.

constant elements with which we have to deal. To put it into the simplest

language we may say that literature names things and that these things are spoken of or described. The knowledge conveyed by literature all has reference either to things or to spoken of, i.e. concretes and processes (§ 298 [emphases his]).

The first of these passages presents concretes and processes as ontological categories that reveal something about the structure of the world as it appears in human experience, embedding them within a model that has struck some commentators as reflecting "the logic of 'Substance' and 'Attribute"" (so Metcalfe 1976, 180) or that of "substance" and "accident" (so Svenonius 1979, $66)$. The second transposes them into what Svenonius $(2000,47)$ has characterized as a "grammatical model", wherein concretes are analogous to subjects and processes, to predicates. (One may note, parenthetically, that Kaiser [1911, § 301] claimed that the concrete-process distinction could not be mapped onto the surface structure of natural language tout court; nevertheless, linguistic considerations do seem to have conditioned his thinking, as is apparent from his characterization of process terms as "terms of action or verbs" [Kaiser 1926, 22-23, $\S$ $7,11])$. Whether viewed in ontological or logico-linguistic terms, this model requires the existence of only two basic categories: concretes and processes. It is little wonder, then, that Kaiser's category system is typically characterized in the literature of knowledge organization (KO) as being dyadic in nature (cf., e.g., Coates 1960, 39; Vlasák 1967, 153; Svenonius 1979, 66-67; Straioto \& Guimarães 2004, 111).

In his final published work, Kaiser $(1926,22 \S \S 6-7)$ intimated that he had originally developed his system around the assumption that the primary categories to be used in systematic indexing would consist simply of concretes ("terms of commodities") and processes ("terms of action or verbs") (cf., Kaiser 1908, § 366, s.v. "Concretes”). However, in his first published discussion of his indexing system, he spoke in terms of three categories: concretes, countries, and processes (Kaiser 1908, $\S \S 114,142-143$ ). Furthermore, in the fuller account of the system that he published three years later, he argued that "[a] statement strictly speaking must always consist of concrete, country and process, but experience will show that often no country is given, and sometimes there is apparently no concrete": in other words, the archetypal form of a statement is the triadic structure Concrete-Country-Process (var., Country-Concrete-Process), with dyadic forms such as Concrete-Process and Country-Process being secondary derivations thereof (Kaiser 1911, $\S \S 302-303$ ). This triadic variant of Kaiser's categorial scheme would reemerge alongside the dyadic version in his final published presentation of his method, which otherwise favored, perhaps for expository purposes at least, the latter (Kaiser 1926, 24-25 § 14$15)$.

Kaiser's theory of systematic indexing, then, featured two different variants of his categorial scheme: one consisting of two categories ("concrete" and "process") and one encompassing three ("concrete", "country", and "process"). Since the only difference between these schemata was that the latter added the category of countries to those of concretes and processes, a harmonization of the two versions was possible: however, it required that the presence of countries in the triadic version be accounted for in a way that would not violate the theoretical assumptions underlying the dyadic scheme. Presumably, it was a desire to carry out such a harmonization that provided the core motivation for Kaiser's attempt at deriving the category of countries from that of concretes. This course of action was not, in itself, unreasonable, for countries can be, in principle, viewed in entitative terms: however, as we have seen, the attempt 
Thomas M. Dousa. 2011. Concretes, countries, and processes in Julius O. Kaiser's Theory of Systematic Indexing: A case study in the definition of general categories. In Smiraglia, Richard P., ed. Proceedings from North American Symposium on Knowledge

Organization, Vol. 3. Toronto, Canada, pp. 160-173.

foundered, largely because of an overly narrowly construal of what a concrete is on the part of Kaiser (cf. Section 3, above).

Given that Kaiser's theoretical articulation of his categorial schema appears to have been originally constructed around the categories of concrete and process alone, we are left with a final question: why did he incorporate the category of countries into his system in the first place? Vlasák $(1967,155)$ has suggested that Kaiser's treatment of countries reflects "a recognition of the significance of geographical concepts, that is specific precisely to subject analysis". Although few would dispute the validity of this observation, it is too general to offer a truly satisfactory rationale for Kaiser's insistence on establishing a separate category for countries. A more compelling explanation can be found by considering, in concreto, the specific milieux within which Kaiser operated. From 1896 to 1899, he worked as an indexer and translator in the Bureau of Information of the Philadelphia Commercial Museum where, by his own account, he developed the first version of his method of systematic indexing (Kaiser 1911, § 20;1926, 20, $\S \S$ 1-3; ASME 1928). Now alongside the Bureau of Information, the Commercial Museum presented exhibits of commercial wares from around the world, which were organized either by type of commodity (i.e., "monographic exhibits") or by geographical provenance (i.e., "geographical exhibits") (Philadelphia Commercial Museum 1896a, 16-17; 1896b, 5-7; Conn 1998, 124). By the same token, the Bureau itself was charged with providing "detailed information ... to manufacturers ... regarding requests for certain products from such-or-such a locality" and the library associated with it was to contain, inter alia, "books about foreign countries ..., as well as maps ..." (Philadelphia Commercial Museum 1896b, 9-10 [emphases mine-TMD]). The museum's policies of exhibit organization, information provision, and library collection all hinged around the assumption that persons with an interest in business required information not only about (types of) commodities but also about the geographical regions that were the sources of, and markets for, commodities. Needless to say, the Commercial Museum's division between "monographic" and "geographic" exhibitions immediately calls to mind Kaiser's categories of concretes-qua-commodities and countries, and it is perhaps not too daring a hypothesis that they may have been a source of inspiration for these categories. At any rate, Kaiser's work at the Philadelphia Commmercial Museum would have underscored for him the significance of geographical concepts within the domain of commerce. The importance of geographical entities would have been further reinforced by Kaiser's subsequent work at the Commercial Intelligence Bureau, Ltd., in London, an organization established along the lines of the Philadelphia Museum (Heindel 1968, 193), and the Tariff Commission, whose informational work focused, as its name suggests, on the import policies of the United Kingdom. In short, Kaiser's inclusion of countries in his categorial scheme is best viewed not as the result of a general appreciation of the value of geographical concepts for subject indexing, but as a historically-conditioned response to the practical interests of the commercial domain within which he worked.

\section{Concluding Remarks}

Throughout his writings, Kaiser invoked the categories of "concrete", "country", and "process" and developed an effective protocol for forming compound subject strings, or statements, on the basis of these categories. From a syntactic point of view, he was quite consistent in his treatment of these categories - concretes and countries, for example, were always given precedence over processes - and this consistency gives his categorial scheme an aura of stability. A close examination of his efforts to define the categories reveals, however, 
Thomas M. Dousa. 2011. Concretes, countries, and processes in Julius O. Kaiser's Theory of Systematic Indexing: A case study in the definition of general categories. In Smiraglia, Richard P., ed. Proceedings from North American Symposium on Knowledge

Organization, Vol. 3. Toronto, Canada, pp. 160-173.

reveals a different story: underneath the surface stability of the terms "concretes", "countries", and "processes", there were semantic tensions that Kaiser was unable fully to resolve. As we have seen, many of these tensions can be attributed to the fact that Kaiser appears to have initially developed his categories within the framework of a specific domain, namely business, but to have sought to establish them as general categories tout court (Kaiser 1911, § 21; 1926, $22, \S 6)$. This two-tiered mode of definition is especially manifest in the case of concretes, which he defined both generally as things in the world that are the objects of observation and reasoning and, much more narrowly, as commodities or things with an exchange value. This mingling of the general and domain-specific definitions under the term "concretes" probably did not affect the practical task of distinguishing terms for concretes from those for processes or countries, but it have deleterious effects on Kaiser's effort to harmonize the dyadic and triadic versions of his category scheme. The tension between a broad definition of concretes qua things tout court and a narrow one of concretes qua commodities could have been mitigated by reducing commodities to a subclass of things and, indeed, it appears that, towards the end of his career, Kaiser $(1926,23, \S$ 10) had, in effect, adopted such a position. Although the generalization of the category beyond "terms for commodities" to include "terms for energies" resolved some difficulties, it arguably did not go far enough, in large measure because the concepts of "commodities" and "energies" had about them a materialist overtone that excluded abstract objects (cf. p. 28, § 24). The very choice of the word "concrete" as the name of the category appears to have been a limiting factor in this and one is justified in wondering if substitution by a different, more general term-such as "entity" or "thing" - might not have allowed Kaiser and users of his system to develop a truly general "entitative" category encompassing both concrete and abstract objects to set against the "verbal" one of processes (cf. Barbour in Kaiser 1926, 39). That, at any rate, was the solution adopted by indexing theorists of a later generation (e.g., Austin 1982, 87).

The tensions in Kaiser's definitions stemmed in large measure from what might be called "semantic overdetermination". In the case of concretes, as we have seen, this overdetermination was caused by a merging of general and domain-specific definitions, whereas in the case of countries and processes, it was caused by the fact that the category was not truly unitary but harbored a number of closely connected, yet distinct, ideas: thus, the category of countries included countries in the strict politico-legal sense as well as larger geographic units and units defined by lack of geographic continuity, while that of processes encompassed both actions and states of being. Kaiser $(1926,28, \S 25)$ himself was aware of these problems and candidly expressed the hope that it would be possible to "make the definitions" of his categories "more precise": however, it is likely that such precision would have been attainable only at the cost of either introducing more subclasses under each of his categories or by importing more categories into the categorial schema, an option that would have compromised his stated aim of limiting it to "a very small number of classes" (p. 28, § 25).

Kaiser's categorial scheme was a site for tension as well. This was occasioned by the synchronous existence of two different versions of his scheme - a dyadic one comprising the categories of concrete and process and a triadic one consisting of concretes, countries, and processes. We have seen that the dyadic scheme was grounded in a theoretical model interpretable from both an ontological and a logico-linguistic perspective-interestingly enough, another example of semantic overdetermination, albeit at a system-wide level. The triadic scheme, on the other hand, introduced a category - that of countries — which had practical salience for indexing within the domain for which Kaiser had designed his indexing method but stood outside of the framework of the theoretical model. Kaiser was thus cast in the position of 
negotiating the tension between theoretical concerns and practical exigencies - $\mathrm{a}$ common experience in the design of KOSs. His attempted solution to merge the two models by deriving the category of countries from that of concretes was sound in principle, but was, in large measure, subverted by his decision to construe the category of concretes as commodities. The fact that Kaiser chose to undertake the effort to harmonize the triadic scheme with the theoretical presuppositions of the dyadic one indicates that he was committed to the latter and so sought to find a way to "save the appearances" of his theory. Nevertheless it is revealing that, whereas he appears to have preferred the simplicity of the dyadic model, he did not reject the triadic scheme. In this, he demonstrated a pragmatic flexibility that doubtless aided him in developing a method of indexing which users found effective in practice (Barbour in Kaiser 1926, 36-39), despite the theoretical difficulties of category definition that we have discussed here.

\section{References}

American Society of Mechanical Engineers. 1928. Necrology: J. O. Kaiser. Record and Index, 1: 265.

Austin, Derek. 1982. Basic concept classes and primitive relations. In I. Dahlberg (ed.), Universal classification 1: subject analysis and ordering systems (Studien zur Klassifikation, Bd. II; pp. 86-94). Frankfurt: Indeks Verlag.

Austin, John. 1873. Lectures on jurisprudence, or the philosophy of positive law $\left(4^{\text {th }}\right.$ ed., revised and edited by Robert Campbell; 2 vols.). London: John Murray.

Barata-Moura, José. 2009. Abstracto/concreto. In R. Reyes et al. (ed.), Diccionario crítico de ciencias socials (pp. 6-19). Madrid: Plaza y Valdés Editores.

Brown, James Duff. 1906. Subject classification with tables, indexes, etc., for the sub-division of subjects. London: The Library Supply Co.

Cheti, Alberto. 1990. Le categorie nell'indicizzazione. Biblioteche Oggi, 8, 29-49.

Coates, E. J. 1960. Subject catalogues: headings and structure. London: The Library Association.

Conn, Steven. 1998. Museums and American intellectual life, 1876-1926. Chicago: The University of Chicago Press.

Cowgill, Jean. 1905. From raw material to finished product. System, 8: 231-242.

Cutter, Charles A. 1904. Rules for a dictionary catalog ( ${ }^{\text {th }}$ ed., rewritten). Washington: Government Printing Office.

Guthrie, Malcolm. 1882. On Mr. Spencer's unification of knowledge. London: Trübner \& Co.

Heindel, Richard Heathcote. 1968. The American impact on Great Britain, 1898-1914: A study of the United States in world history. New York: Octagon Books.

Hunter, Robert, \& Morris, Charles (eds.). 1897. Universal dictionary of the English language (4 vols.). New York: Peter Fenelon Collier.

Joseph, H. W. B. 1906. An introduction to logic. Oxford: Clarendon Press.

Kaiser, J. 1908. The card system at the office. London: McCorquodale.

Kaiser, J. 1911. Systematic indexing. Isaac Pitman \& Sons.

Kaiser, J. 1914. Le système de la carte au bureau. (O. Leroy, trans.). Paris: G. et M. Ravisse. Kaiser, J. 1926. Systematic indexing. In The Association of Special Libraries and Information Bureaux. Report of the Third Conference held at Balliol College, Oxford, September $24^{\text {th }}$ $27^{\text {th }}, 1926$ (pp. 20-44). London: The Association of Special Libraries and Information Bureaux. 
Thomas M. Dousa. 2011. Concretes, countries, and processes in Julius O. Kaiser's Theory of Systematic Indexing: A case study in the definition of general categories. In Smiraglia, Richard P., ed. Proceedings from North American Symposium on Knowledge Organization, Vol. 3. Toronto, Canada, pp. 160-173.

La Barre, Kathryn. 2010. Facet analysis. Annual Review of Information Science and Technology, 44: 243-284.

Martin, Friedrich. 1892. Schulgrammatik der deutschen Sprache (5., durchgesehene Auflage). Breslau: Ferdinand Hirt, Königliche Universitäts- und Verlags-Buchhandlung.

Metcalfe, John. 1976. Information retrieval, British \& American, 1876-1976. Metuchen, N.J.: The Scarecrow Press.

Mill, John Stuart. 1874. A system of logic, ratiocinative and inductive: being a connected view of the principles of evidence and the methods of scientific investigation ( $8^{\text {th }} \mathrm{ed}$.). New Yorker: Harper \& Brothers.

Philadelphia Commercial Museum. 1896a. Proceedings of the First Annual Meeting of the Advisory Board of the Philadelphia Museums. [Philadelphia: The Philadelphia Museums].

Philadelphia Commercial Museum. [1896b]. The Philadelphia museums: The Commercial Museum (Spanish ed.). [Philadelphia: The Philadelphia Museums].

Pope, Jesse Eliphalet. 1905. The clothing industry in New York (University of Missouri Studies, Social Science Series, Vol. 1). [Columbia, MO]: University of Missouri, 1905

Read, Carveth. 1898. Logic, deductive and inductive. London: Grant Richards.

Rescher, Nicholas. 1996. Process metaphysics: an introduction to process philosophy. Albany, NY: State University of New York Press.

Robinson, William C. 1900. Elements of American jurisprudence. Boston: Little, Brown, \& Co.

Ryland, F. 1900. Logic: an introductory manual for the use of university students. London: George Bell \& Sons.

Salmond, John W. 1907. Jurisprudence, or the theory of the law ( $2^{\text {nd }}$ ed.). London: Stevens and Haynes.

Simpson, J. A., \& Weiner, E. S. C. (eds.). 1989. Oxford english dictionary ( ${ }^{\text {nd }}$ ed.; 20 vols.). Oxford: Clarendon Press.

Speiss, Moritz, \& Berlet, Bruno. 1869. Deutsche Schulgrammatik für höhere Schulen: Zweiter Kursus, für den Unterricht in mittleren Klassen berechnet (3. Auflage). Bildburghausen: Ludwig Ronne's Verlag.

Stock, St. George. 1888. Deductive logic. London: Longmans, Green, \& Co.

Straioto, Ana Claudia, \& Guiamarães, José Augusto Chaves. 2004. A abordagem facetada no contexto da organização do conhecimento: elementos historicos. Páginas $a \& b, 14: 109$ 136.

Svenonius, Elaine. 1979. Facets as semantic categories. In W. Dahlberg, Klassifikation und Erkenntnis II (Studien zur Klassifikation, 5; pp. 57-79). Frankfurt: Gesellschaft für Klassifikation.

Svenonius, Elaine. 2000. The foundation of information organization. Cambridge, MA/London: The MIT Press.

Vlasák, Rudolf. 1967. Kategoriový rozbor pojmů a stavba předmětového hesla. Knihovna, 7: $141-185$.

Whitney, William Dwight, \& Smith, Benjamin E. (eds.). 1911). The century dictionary and cyclopedia (Revised and enlarged ed.; 12 vols.). New York: The Century Co.

Zikmund, Václav. 1876. Mluvnice jazyka českého pro střední školy (3. Vydání). Praha: I. L. Kober. 